\title{
Model testing on rainfall-induced landslide of loose soil in Wenchuan earthquake region
}

\author{
H. Fang ${ }^{1,2}$, P. Cui ${ }^{1}$, L. Z. Pei ${ }^{1,2}$, and X. J. Zhou ${ }^{1,2}$ \\ ${ }^{1}$ Institute of Mountain Hazards and Environment, Key laboratory of Mountain Hazards and surface processes, Chinese \\ Academy of Sciences, Chengdu 610041, China \\ ${ }^{2}$ Graduate University of Chinese Academy of Sciences, Beijing 100049, China
}

Correspondence to: H. Fang (fanghuihuahust@ 163.com)

Received: 2 July 2011 - Revised: 5 January 2012 - Accepted: 10 January 2012 - Published: 1 March 2012

\begin{abstract}
This study investigates the formation process of rainfall-induced landslide for slopes composed of loose soil in the Wenchuan earthquake region. Experimental investigations have been performed on the landslide's formation and the variation of the controlling soil parameters under various artificial rainfall conditions. The landslide triggering mechanisms can be described in the following way. Firstly, the large porosity of the loose soil facilitated the infiltration of water, which increased the pore water pressure and reduced the shear strength of the soil significantly. In addition, the rainfalls probably caused the concentration of finer particles at a certain depth of the valley slopes. This concentration within the soil increased the pore water pressure significantly, and consequently reduced both the porosity ratio and permeability. Therefore, when the pore water pressure reached a critical state, the effective shear strength of the soil diminished, inducing the landslide's formation.
\end{abstract}

\section{Introduction}

In 2008, the Wenchuan region (China) was strongly affected by a strong earthquake. The earthquake reached an intensity of $M_{\mathrm{S}}=8.0$, and caused many landslides and soil collapses. The landslides caused extensive damage throughout the Wenchuan region to roads, connections, houses, infrastructures, endangering people and inhabited areas. For example, the Doujiangyan-Whenchuan highway was blocked many times. On 24 September 2008, long-time torrential rain spoiled the loose deposit material and triggered a landslide which converted quickly to a debris flow at the Xishan slope of Beichuan County. The landslide and debris flow caused 44 fatalities and buried dozens of houses (Tang et al., 2008). Landslides and debris flows have been caused by loose soil, which spilled easily from hillslopes and was triggered again into motion. Soil spilling was generally due to the soil's low strength and its critical state of instability (Cui et al., 2008). This type of rainfall-induced landslide has become one of the most typical landslides which occurrs in high frequency, wide distribution, and complex failure modes after the earthquake (Yin et al., 2009). The spatial distribution of rainfalls in 2008 was mainly influenced by the fault structure, formation lithology, terrain slope and river system, and the influencing factors are from geological processes of the earth's inner power transferred to the geological processes of the topographical factor's external power (Huang et al., 2009).

Rainfall is the main cause of landslide, especially for shallow slides (Sassa, 1988; Wang, 2003; Cui, 2009; Yin, 2009). The present experimental study on the landslide under rainfall condition concluded that:

1. The rainfall penetrates into the potential landslide, increases the soil bulk density, softens the soil, reducing the stabilizing force of the soil;

2. The rainfall increases the pore water pressure rapidly, which diminishes the effective stress and shear strength in the potential sliding surface (Iverson, 2000; Gabet, 2006);

3. The fallback of the groundwater level causes the soil water-release compression; this induces the slope subsidence and leads to the cracks and fractures in slope; even the raising of the groundwater level generates great uplift force to the soil, causing instability (Chen, 2006; Cui, 2009);

4. The shallow landslides are usually a result of liquefaction, a process during which a high excess pore water pressure is generated, and the soil mass suddenly loses a large proportion of its shear resistance and flows in a manner resembling a liquid. Liquefaction of sands due 
to cyclic loading has received a great deal of attention since the Niigata, Japan, earthquake of 1964 (Yoshimi et al., 1977; Seed, 1979; Finn, 1981). In addition, the static liquefaction due to a monotonic increase of the static loading has been studied in recent years (Castro, 1969; Casagrande, 1976; Poulos, 1981; Poulos et al., 1985).

This study investigates the initiation process, controlling factors, and mechanism of the landslides for the deposit materials under rainfall condition, using material from the slope in a typical earthquake region.

\section{Experimental program}

\subsection{Experimental equipment}

\section{Test flume}

Based on an extensive post-earthquake survey and related literature review (Cui et al., 1992; Kaitan et al., 2007; Wang et al., 2003), the authors find that most of the rainfall induced landslides were surface-layer-disturbed-soil landslides, and their slope gradient ranges from $15^{\circ}$ to $30^{\circ}$. Moreover, on slopes greater than $30^{\circ}$, in the Wenchuan region, the soil deposits are very thick and abundant and on these slopes the erosion was revealed to be very strong. In addition, during the 2008 disaster, most of the failures transformed into debris flows, causing intense gully erosion (Cui et al., 2010). Considering the natural conditions occurring in the Wechuan region, the authors designed a straight oblique small-scale device, as illustrated in the Fig. 1. This equipment comprises a rectangular plexiglass flume with dimension of $300 \mathrm{~cm} \times 35 \mathrm{~cm} \times 35 \mathrm{~cm}$, a manual variable slope mast and some plates. Also, an additional $5 \mathrm{~mm}$ thick antiskid tread plate for the bottom has been prepared (Cui et al., 1992).

\section{Artificial rainfall system}

The experiment utilizes an artificial rainfall device, designed by the Institute of Soil and Water Conservation, CAS. The raindrop size distribution and impact energy under different rainfall intensity have been calibrated so that the spray nozzle simulates well the rainfall effects. The system includes a submersible pump, a diversion box, a spray nozzle, a spray pipe, and a bracket (Fig. 2). The size of the nozzle ranges from 5 to $11 \mathrm{~mm}$, so that different rainfall intensity, from sprinkle to torrential rain, can be simulated.

\section{Test sensors}

The internal soil parameters including the water content and pore water pressure were measured during the test. At the same time, a real-time video recorded the sliding process.

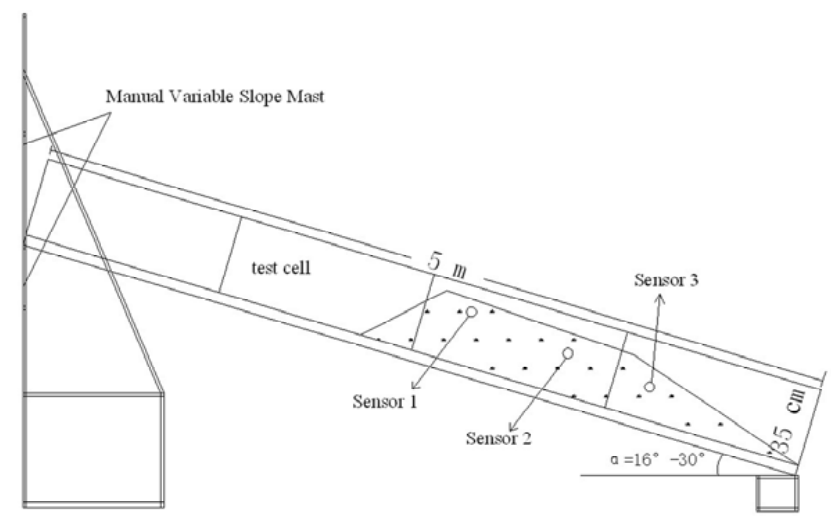

(a) The test flume

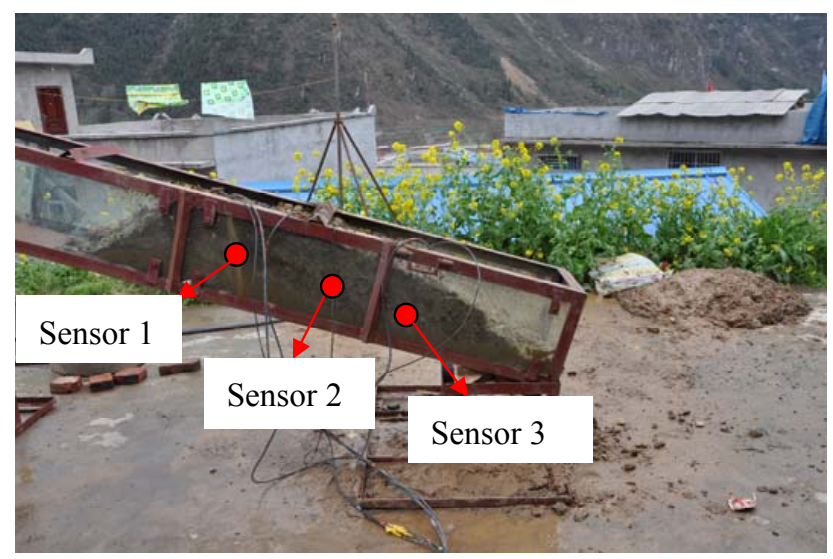

(b) The loose soil and sensors

Fig. 1. The experimental setup.

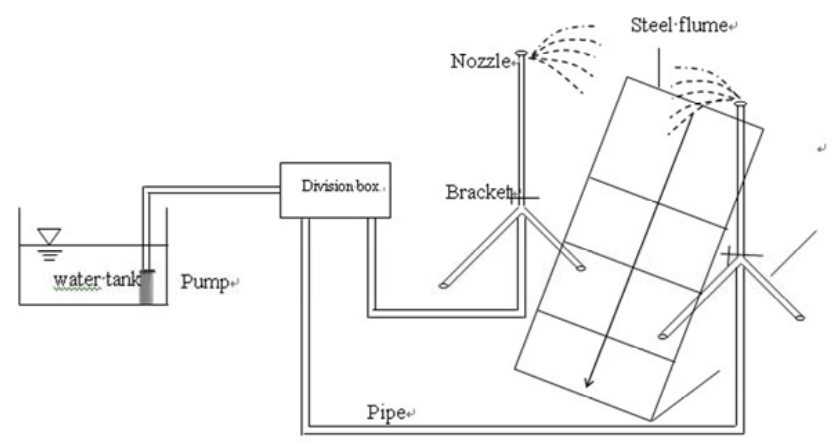

Fig. 2. The artificial rainfall system.

TRASETDR (manufactured in the USA) was used in the experiment to measure the water content designated as volumetric water content, which is able to scan 12 channels in every minute. In addition, the PSI Pressure system, also produced in the USA, was adopted to measure water pressure with an accuracy of 5.0 $\mathrm{Pa}$ (Chen et al., 2006). 


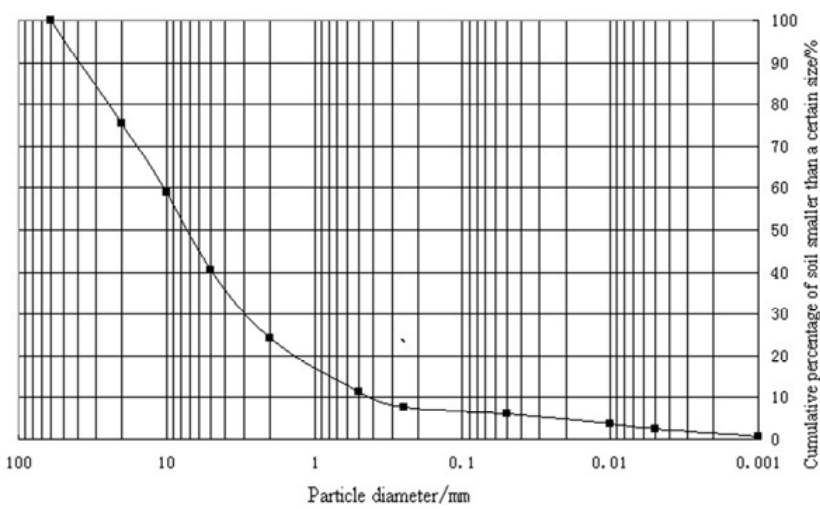

Fig. 3. Grain-size distribution for the sample soil.

\subsection{Soil samples}

Since this study focuses on landslides composed of postearthquake-disturbed soil under rainfall conditions, the soil samples were taken from Weijiagou gully, which is frequently affected by debris flow. The grain-size distribution is shown in the Fig. 3, which shows that the disturbed soil is a typical, wide-grading-gravel-soil. The clay content is low and most grain is gravel. Because the grain content determines the mechanical properties of soil, the lower clay content in the current soil results in smaller internal cohesion and internal friction angle as compared with normal soft clay. In addition, the soil properties largely influence the stability mode and failure mechanism for landslides under rainfall (Iverson et al., 2000).

The tests were performed following these steps:

- A moderate amount of water was added into soil to obtain a homogeneous mixture;

- A certain gradient slope was kept for the soil at the bottom of flume to create the same condition as the natural state;

- A 3-5 day consolidation process for the soil and slope was carried out in order to make the soil recover its root position state as much as possible (Wang et al., 2009).

In addition, three group of sensors were pre-embedded at the forehead, middle and bottom of the sliding surface with the laying depth of $10-15 \mathrm{~cm}$, to measure the water content and pore water pressure.

\section{Experimental phenomena}

The experiment adopts a high rainfall intensity of $84 \mathrm{~mm} \mathrm{~h}^{-1}$ and considers three different slope gradients of $16^{\circ}, 22^{\circ}$ and

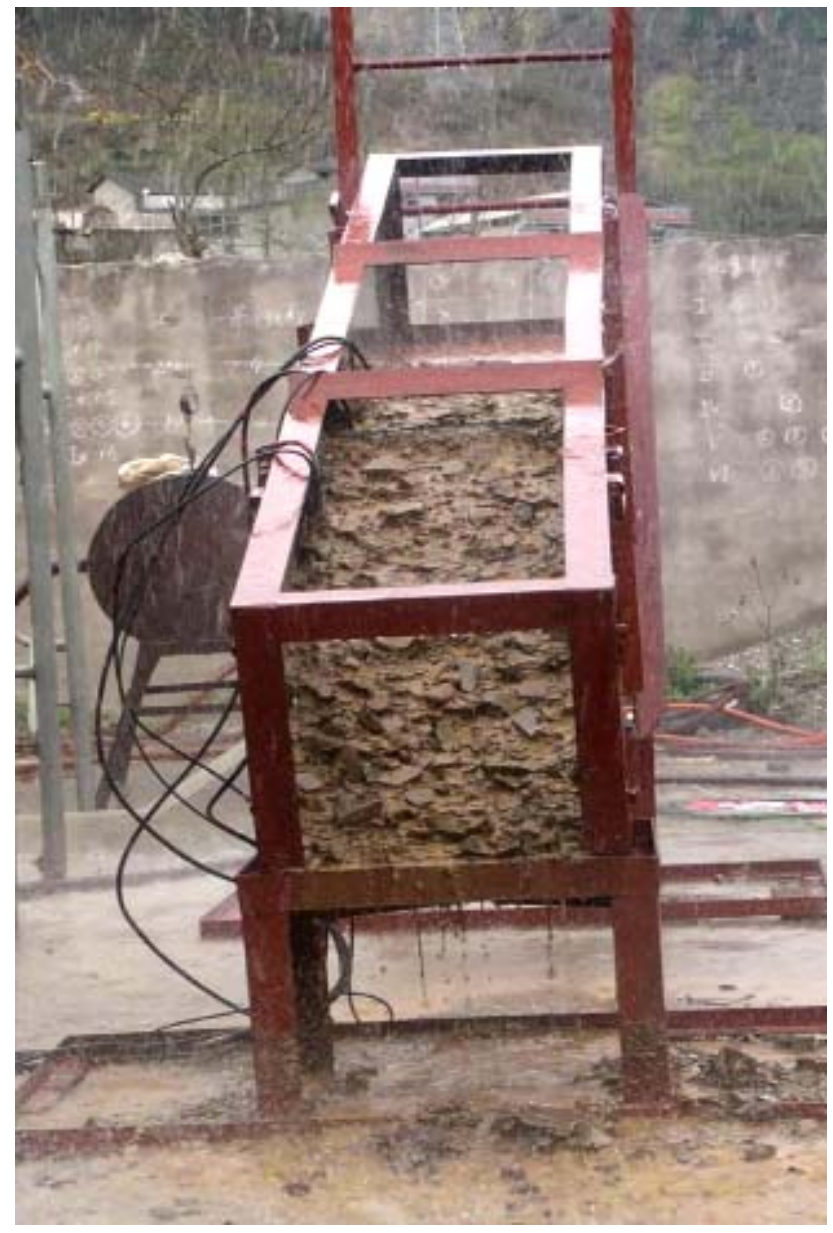

Fig. 4. Fine particulate matter is transferred and taken away.

$30^{\circ}$. The failure process of the soil and slopes can be summarized as follows.

At the beginning of the rainfall, the water directly penetrates into the soil without any surface runoff and a fraction of the fine grains rolls on the slope surface. When the rainfall increases, a runoff is generated on the soil surface. The runoff scoures and takes away fine particles, then the soil moves down slowly, with coarse grains and gravels exposed. When the rainfall increases, the sliding velocity gradually gets faster and faster, together with some stone block falling to the ground from the bottom of slope (outside the flume). When the rainfall duration reaches about 20-40 min (depending on slope gradient), part of the soil collapses, sliding down along the slope (Figs. 4-6). The soil failure progresses upstream, and then successive landslides with the continuing rainfall for the soil stress are quickly released continuously on the slope.

Comparison between three tests $\left(16^{\circ}, 22^{\circ}\right.$ and $\left.30^{\circ}\right)$ shows that the phenomena were much the same at the beginning of rainfall. The main difference lies in the sliding process and the rainfall duration before the landslide happened. 


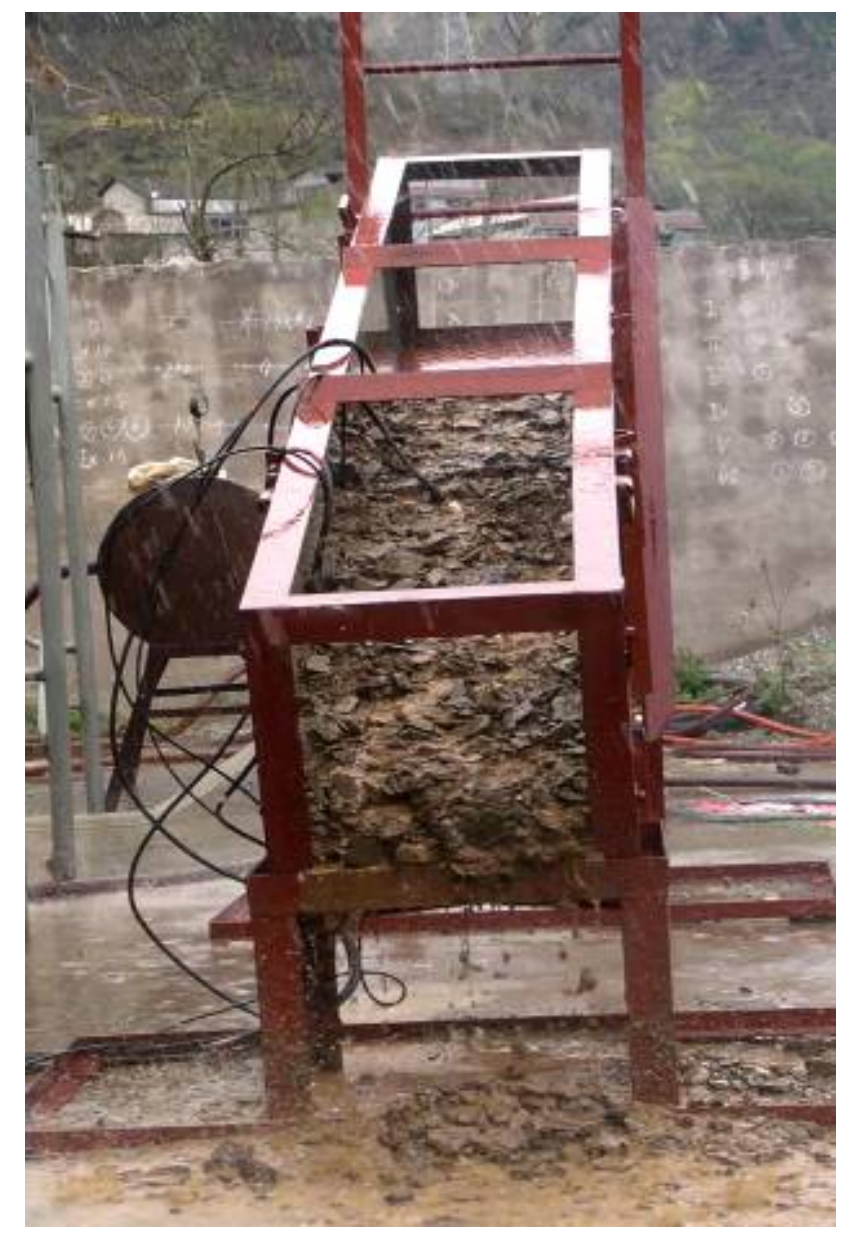

Fig. 5. Soil slides down slowly and goes gradually faster.

When the slope gradient was $16^{\circ}$, the soil slid down slowly and repeatedly, and it took $40 \mathrm{~min}$ of rainfall for the landslide process. When the slope gradient was $22^{\circ}$, the sliding process finished integrally at one time, but the landslide size and slide velocity were much larger than those of the slope with gradient $16^{\circ}$. Actually, the landslide occurred after a duration of $18 \mathrm{~min}$ of rainfall. When the slope gradient was $30^{\circ}$, the situation was very similar to the first and second test. The landslide occurred after a duration of $18 \mathrm{~min}$ of rainfall.

\section{Analysis of the experimental data}

\subsection{Water content}

Generally, the water content directly influences the soil's physical and mechanical properties. Firstly, it reflects the water infiltration rate and soil structure. Moreover, the greater the water content of soil, the lower the shear strength is and therefore, the slope stability is less (Hotta et al., 2000). During the experiment, the water content data from three groups of sensors were picked once per minute, and the results are presented in Figs. 7-9.

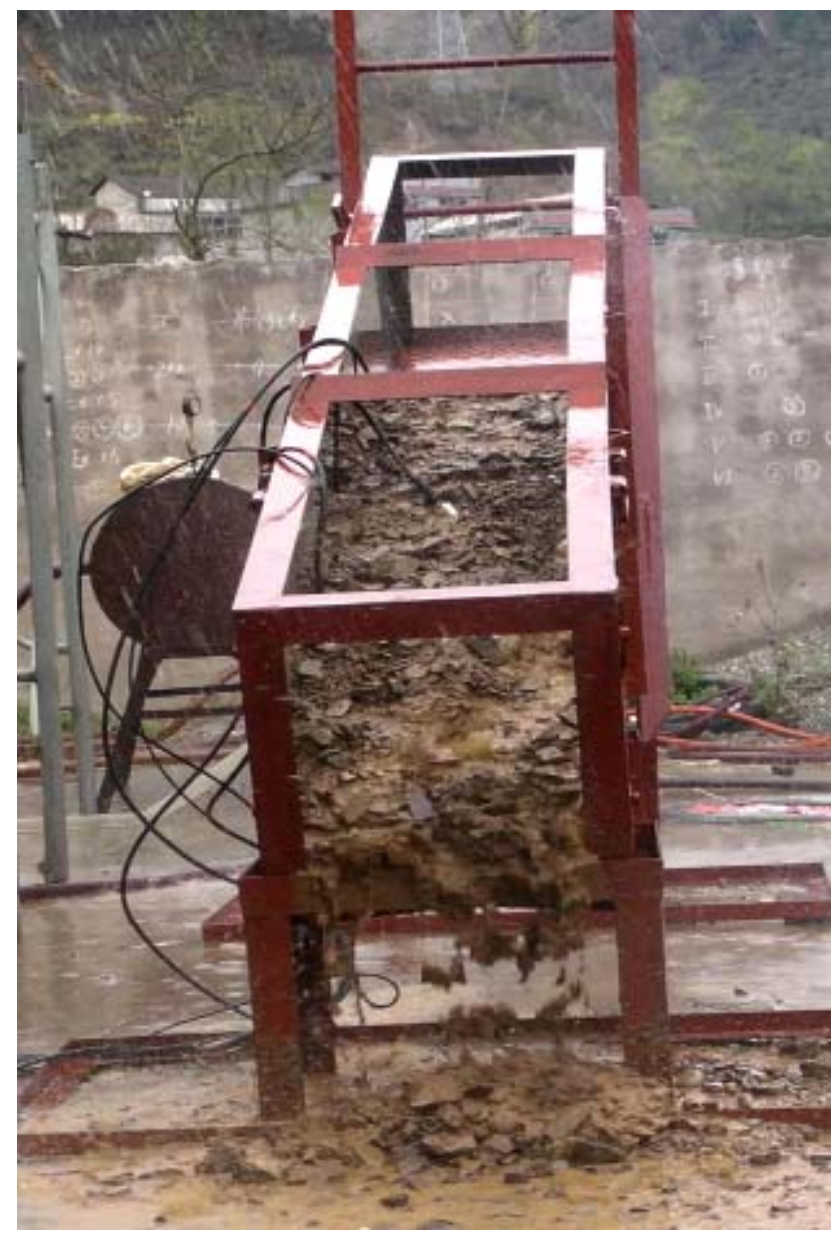

Fig. 6. Soil slides down sharply and landslide occurres.

Figures 7-9 show the changes of water content of soils for three test cases, that is for three bed slopes. At the first stage of the test, the rainfall penetrated into the soil and made the water content of surface soil increase rapidly. Then the water seeped into the soil from the surface to the internal soil until the soil became saturated. In the final stage, the water content tended to reach a relatively stable state, except for the sensor 3, where the water content increased faster than for other two sensors. Actually, sensor 3 was buried at the bottom of the slope.

\subsection{Pore water pressure}

Generally, in natural slopes, a boundary line divides the unsaturated soil and the saturated soil. Above the line, the pore water pressure of the unsaturated soil is negative, while the water pressure of the saturated soil below the boundary line is positive (Fredlund et al., 1997). Due to the experimental conditions, no homogeneous saturation conditions were reached in the tests. Moreover, due to the short consolidation time, the soil's matrix suction was still in the preliminary 


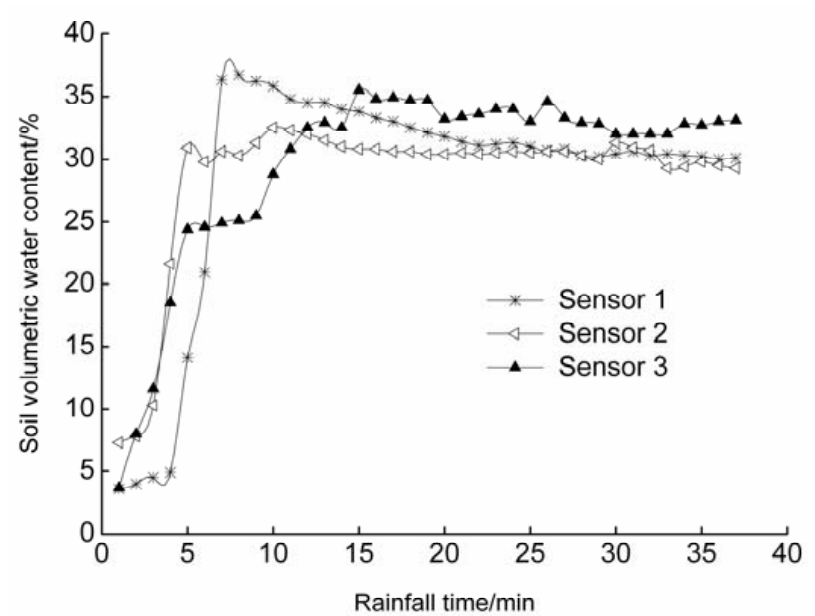

Fig. 7. The change of water content in the soil during the landslide process for the slope with gradient of $16^{\circ}$.

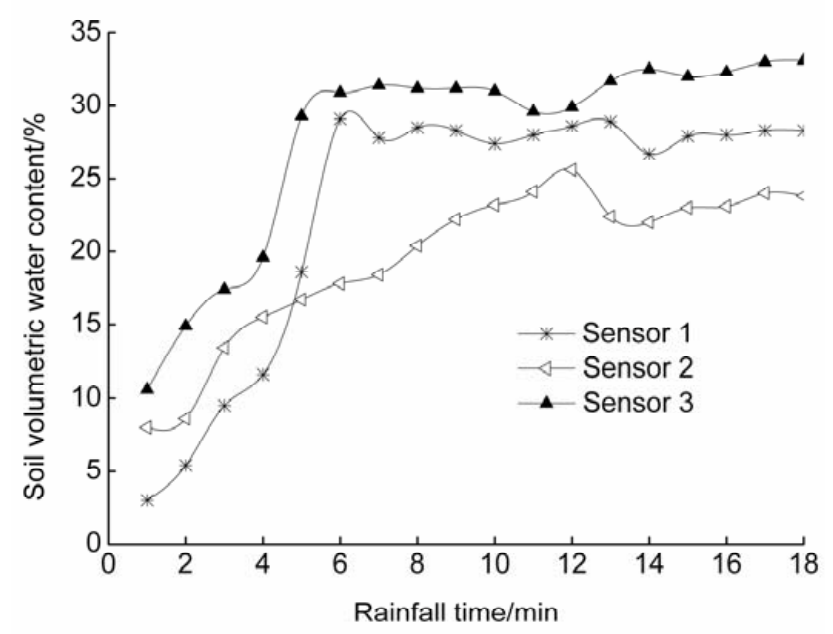

Fig. 8. The change of water content in the soil during the landslide process for the slope with gradient of $22^{\circ}$.

formation stage. This is confirmed by the data collected every two seconds in each sensor, and the results are presented in Figs. 10-12.

Figure 10 shows that the inner pore water pressure of the soil at gradient $16^{\circ}$ increased steadily. The main reason is that the soil experienced shear contraction during the shear deformation process, which made the pore water pressure increased constantly until the sliding failure of the soil.

Figures 11 and 12 demonstrate that the pore water pressure increases at the initiate stage of rainfall, then decreases to some level and again increases finally, until the failure of the soil slope. Probably the main reason is that the soil shear dilatation induced a pore water pressure decrease. After this stage, the soil turned to experience shear contraction as the rainfall continued. The sensors were exposed when the land-

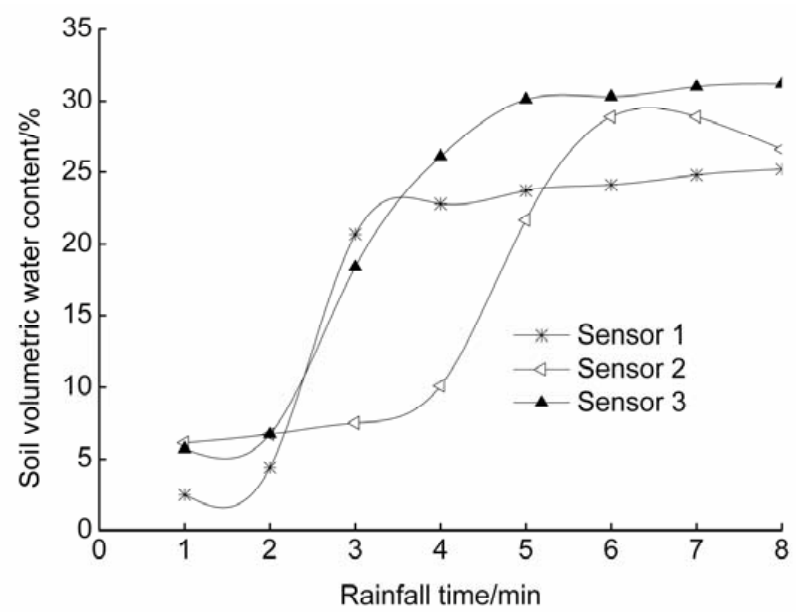

Fig. 9. The change of water content in the soil during the landslide process for the slope with gradient of $30^{\circ}$.

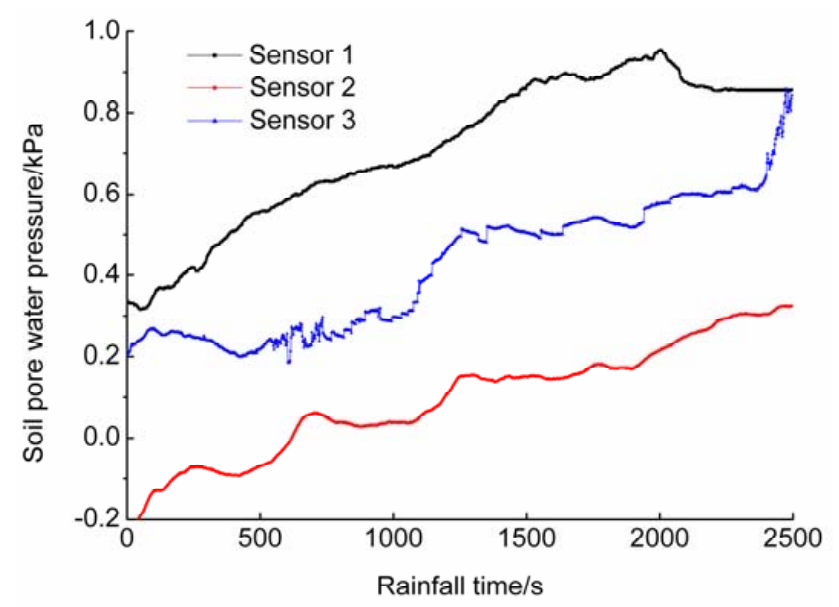

Fig. 10. The change of pore water pressure in the soil during the landslide process for the slope with gradient of $16^{\circ}$.

slide happened; therefore some monitoring data was not very accurate after the sliding. So we only monitored the pore water pressure before the soil sliding, and the data mostly reflected the changes of pore water pressure before landslide.

The different behaviour of the slopes, as far as dilatation and contraction are concerned, can be explained as follows:

- At the slope gradient of $16^{\circ}$, the soil is under higher stress levels (the soil normal stress $\sigma=\rho g h \cos \theta$, where $\theta$ is the slope gradient), so the soil experienced a shear contraction phenomenon;

- At the slope gradient of $30^{\circ}$, the soil is under lower stress levels and therefore it tended to show the shear dilatation phenomenon (Iverson et al., 1989; Sassa et al., 2000). 


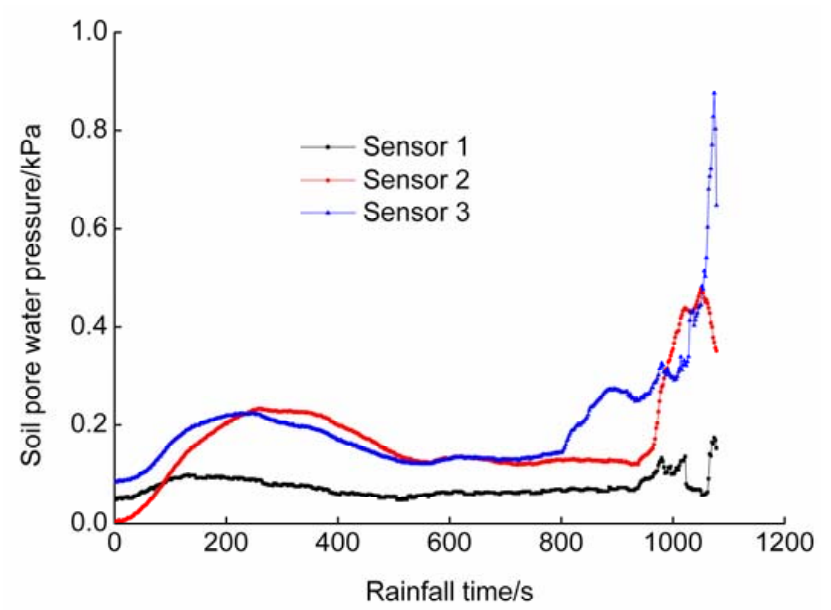

Fig. 11. The change of pore water pressure in the soil during the landslide process for the slope with gradient of $22^{\circ}$.

This is why the soil tended to shear dilatation at the slope gradient of $22^{\circ}$ and $30^{\circ}$ but shear contraction at the slope gradient of $16^{\circ}$.

\section{Deformation failure model for rainfall-induced landslide of loose soil}

Based on the model experiment and on the data on the variation of water content and pore water pressure during the failure process, the following deformation-failure model for the rainfall-induced landsides can be proposed.

a. Water infiltrating: The water content and the pore water pressure of soil increases rapidly at the first stage because of the large pore size in loose soil such that the water can penetrate easily into the soil and seep along, which makes the slope turn into the self-organized, critical condition and results in shear deformation.

b. Fine-particle transferring and accumulating. The fine particles begin to move with the water infiltrate and flow: part of the fine particles are transferred onto the surface of the soil, and other fine particles are transferred into the slope with the water seepage. The fine particles accumulate at a certain plane in the soil eventually and block the penetration route of water, which decreases the soil porosity at the soil plane. This results in the corresponding rapid increase of soil water content and pore water pressure.

c. Soil effective strength diminishing: The increase in water content and pore water pressure cause the decreasing and diminishing of the soil's effective stress and shear strength at the plane where the fine particles are accumulated in the soil, and then the soil collapses, sliding down along the plane and landslide occurs.

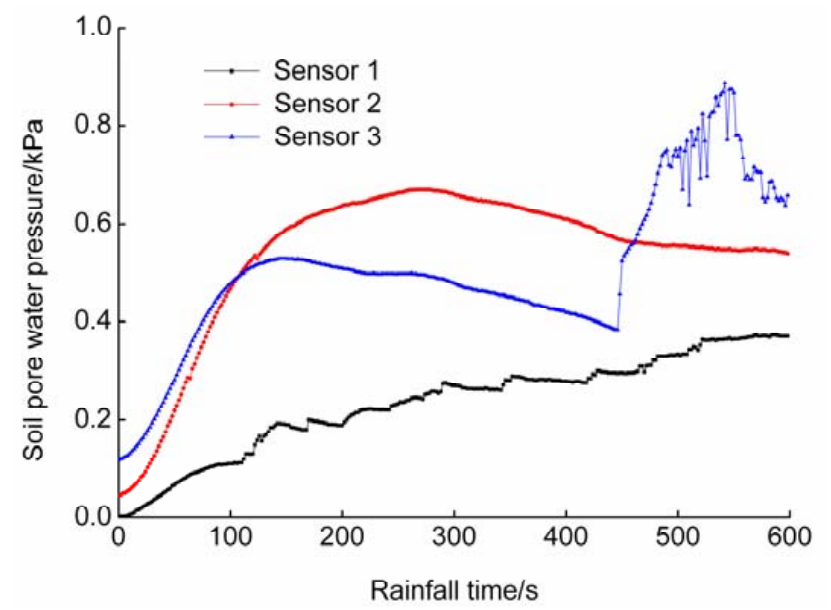

Fig. 12. The change of pore water pressure in the soil during the landslide process for the slope with gradient of $30^{\circ}$.

The truth is that the plane with accumulated fine particles is a potential weak sliding surface. It has been observed by the experimental observations after the test that lots of fine clay materials at the sliding surface were observed, as shown in Fig. 6. It has been observed by the experimental observations after the test that lots of fine clay materials at the sliding surface were observed in the experiment following the test, as shown in Fig. 6.

\section{Conclusions}

The loose deposit generated by the co-seismic collapses and landslides during the Wenchuan Earthquake has a very low mechanical intensity and can be easily undermined to cause landslides with fatalities during rainfall. The deformation failure mode of such a landslide is different from the coseismic landslides and many other landslides. The slide face is facilitated by the fine particles, which are transferred into the soil and accumulated eventually at a certain plane. The authors name the above observation as the fine-particleaccumulation-inducing blocking phenomenon.

The experimental results indicate that the accumulation of fine particles, which block the infiltration channel in the soil, results in a sharp increase in water content and pore water pressure. The effective shear strength of the soil reduces gradually until a critical state, i.e. when the self weight of the soil is balanced by the pore water pressure, is reached. At the first stage of failure, the soil on the top of the slope spoils and moves down to release stress on the slope. Then, the soil slides onto the plane with a large amount of fine particles and eventually, landslide occurs.

For further research, the authors suggest that researchers should take into account the runoff of the soil under excessive infiltration and the fine-particle-accumulation-induced 
blocking phenomenon. In addition, the partition of soil and water is necessary to prevent the rainfall-induced landslide for disturbed soil slopes.

Acknowledgements. Financial support from the National Basic Research Program(973) project (2011CB409902) and the National Natural Science Foundation of China (No.40801009) is gratefully acknowledged.

Edited by: L. Franzi

Reviewed by: S. Cao and another anonymous referee

\section{References}

Castro, G.: Liquefaction of sands, $\mathrm{PhD}$ thesis, Harvard University, 1969.

Casagrande, A.: Liquefaction and cyclic mobility of sands: a critical review, Harvard Soil Mechanics Series, 88, Harvard University, 1976.

Chen, Y.: An Influence of Earthquake on the Occurrence of Landslide and Debris Flow D, Hydraulics \& Ocean Engineering, Taipei, National Cheng Kung University, 2008.

Cui, P.: Studies on condition and mechanism of debris flow initiation by means of experiment, Journal of Chinese Science Bulletin, 379, 759-763, 1992.

Cui, P., Chen, X. Q., Zhu, Y. Y., Su, F. H., Wei, F. Q., Han, Y. S., Liu, H. J., and Zhuang, J. Q.: The Wenchuan Earthquake May 12, 2008, Sichuan Province, China, and Resulting Geohazards, J. Nat. Hazards, doi:10.1007/s11069-009-9392-1, 2009.

Cui, P., Zhuang, J. Q., Chen, X. C., Zhang, J. Q., and Zhou, X. J: Characteristics and Countermeasures of Debris Flow in Wenchuan Area After the Earthquake [J], Journal of Sichuan University, Engineering Science Edition, 42, 10-19, 2010.

Chen, X. Q., Cui, P., Feng, Z. L., Chen, J., and Li, Y.: Artificial rainfall experimental study on landslide translation to debris flow [J], Chinese Journal of Rock Mechanics and Engineering, 251, 106-116, 2006.

Gabet, E. J. and Mudd, S. M.: The mobilization of debris flows from shallow landslides, J. Geomorphology, 74, 207-218, 2006.

Fredlund, D. G. and Rahardjo, H.: Soil mechanics for unsaturated soils [M], edited by: Chen, Z. Y., Zhou, J. X., and Wang, H. J., translator, Beijing: China Architecture and Building Piess, 1997.

Hotta, N. and Ohta, T.: Pore-water Pressure of Debris flows [J]. Physics and Chemistry of the Earth, Part B: Hydrology, Oceans and Atmosphere, 25, 381-385, 2000.

Hu, M. G., Wang, R., and Zhang, P. C.: Cause of Frequent Occurrence of Gravel Slope Landslide and Experiment Simulation, J. Chinese Journal of Rock Mechanics and Engineering, 2112, 1831-1834, 2002.
Huang, T., Zhang, Z., Gu, Y. Q., Zhou, M. D., and Qiang, J. H.: Distributed characteristics research of earthquake-induced secondary geological disasters in BeiChuan County:Based on GIS and remote sensing, J. Remote Sens., 2009, 131, 177-182, 2009.

Iverson, R. M., Reid, M. E., Iverson, N. R., LaHusen, R. G., Logan, M., Mann, J. E., and Brien, D. L.: Acute sensitivity of landslide rates to initial soil porosity, Journl of Science, 290, 513-516, 2000.

Iverson, R. M. and Lahuse, R. G.: Dynamic pore-presure fluctuation in rapidly shearing granular materials[J].Science, 246, 796-799, 1989.

Kaitna, R., Rickenmann, D., and Schatzmann, M.: Experimental study on rheologic behaviour of debris flow material, J. Acta Geotechnica, 2, 71-85, 2007.

Poulos, S. J.: The steady state of deformation, J. Geotech. Eng. Div. ASCE, 107, No. GT5, 553-562, 1981.

Poulos, S. J., Castro, G., and France, J. W.: Liquefaction evaluation procedure, J. Geotech. Eng. Div. ASCE, 111, 6, 772-792, 1985.

Sassa, K.: Special lecture: Geotechnical model for the motion of landslides [A], Int. Proc. 5th International Symposium on Landslide, 1C, Rotterdam, A. A. Balkema, 37-55, 1988.

Sassa, K.: Mechanism of flows in granular soils [A], in: GeoEng2000-An International Conference on Geotechnical and Geological Engineering, 1, Invited Papers [C], Lancaster, Pennsylvania: Technomic Publishing Co. Inc, 1671-1702, 2000.

Seed, H. B.: Soil liquefaction and cyclic mobility evaluation for level ground during earthquakes, J. Geotech. Eng. Div. ASCE, 105, 201-255, 1979.

Tang, C.: Activity tendency prediction of rainfall induced landslides and debris flows in the Wenchuan Earthquake areas, J. Mt. Sci., 28, 341-349, 2010.

Tang, C. and Liang, J. T.: Characteristics of Debris Flows in Beichuan Epicenter of the Wenchuan Earthquake Triggered by Rainstorm on September 24, 2008, J. Eng. Geol., 166, 751-758, 2008.

Wang, G. H. and Sassa, K. Pore-presure generation and movement of rainfall-induced landslides: effecrs of grain size and fineparticle content, J. Eng. Geol., 69, 109-125, 2003.

Xu, Q., Pei, X. J., and Huang, R. Q.: Large-scale Landslides Induced by the Wenchuan Earthquake, M, Beijing, Science Press, 19-29, 2009.

Yin, Y. P.: Features of landslides triggered by the Wenchuan Earthquake [J], J. Eng. Geol., 171, 29-38, 2009.

Yoshimi, Y., Richart, F. E., Prakash, S., Balkan, D. D., and Ilyichev, V. A.: Soil dynamics and its application to foundation engineering, Proc. 9th Int. Conf. Soil Mech., 2, 605-650, 1977. 